\title{
Stroke awareness in a Sri Lankan community
}

\author{
Ranawaka $\mathbf{U} \mathbf{K}^{1}$, de Silva $\mathbf{H}^{1}$, Balasuriya $\mathbf{J}^{1}$, Puvanendiran $\mathbf{S}^{1}$, Jayasekara $\mathbf{B}^{1}$, Wijesekera $\mathbf{J} \mathbf{C}^{1}$ \\ Journal of the Ceylon College of Physicians, 2016, 47, 31-35
}

\begin{abstract}
Objective: Knowledge regarding stroke is likely to influence treatment seeking and preventive behaviour. We sought to assess stroke awareness in a Sri Lankan community.

Methods: Adults and schoolchildren in 750 households in the Kelaniya Medical Officer of Health area selected by cluster sampling formed the study population. Knowledge about stroke was assessed using a pre-tested, structured, interviewer administered questionnaire. Level of knowledge was categorised into five groups using a composite score.
\end{abstract}

Results: 711 adults and 155 schoolchildren were studied. Only $36.8 \%$ recognised the brain as the organ involved in a stroke. Main presenting symptoms identified were unilateral weakness (93.9\%) or sensory symptoms (88\%), and speech difficulty (88\%). Stroke was considered a cause of sudden death by $58.4 \%$. Many recognised hypertension (74.3\%) as a risk factor, but awareness was inadequate regarding diabetes $(60.5 \%)$, heart disease $(60.9 \%)$, hypercholesterolaemia $(62.5 \%)$ and smoking (61.3\%). Of the respondents, $60.1 \%$ considered stroke was preventable, $74 \%$ were aware that stroke could recur, $91.3 \%$ believed early treatment would improve outcome and $88.8 \%$ considered stroke an emergency.

Level of knowledge was considered 'good' in $43.3 \%$, and 'very good' in only $0.7 \%$. Majority were graded as average (46.8\%), 'poor' (5.9\%) or 'very poor' (3.4\%). There was no significant difference in knowledge between adults and schoolchildren. Having a friend or a relative with

\footnotetext{
${ }^{1}$ Institute of Neurology, National Hospital of Sri Lanka, Colombo.

Corresponding author: UKR

E-mail: udayaran@yahoo.com
}

a stroke was the commonest source of knowledge (61.5\%). Doctors (32.2\%) and other health workers (9.1\%) were poor sources of information.

Conclusions: Knowledge about stroke is deficient in many aspects. Health professionals need to play a greater role in improving awareness.

Key words: stroke, knowledge, awareness, developing country, Sri Lanka

\section{Introduction}

Stroke is a major global health problem. It causes significant mortality, being the second leading cause of death worldwide, ${ }^{1}$ and the fourth leading cause of in-hospital deaths in Sri Lanka. ${ }^{2}$ The main impact of stroke on society, however, is largely due to the residual disability and dependency it creates, with half of the survivors being dependent on others at one year after a stroke. ${ }^{3}$

Available community data suggest that Sri Lanka has one of the highest prevalence rates of stroke in the world. ${ }^{4,5}$ Furthermore, Sri Lanka has a rapidly ageing population, ${ }^{6}$ and vascular risk factors such as hypertension, diabetes and smoking are on the increase. ${ }^{7}$ The burden of stroke is likely to increase dramatically as a result, and the available health care systems are ill equipped to meet this challenge. A previous audit has shown significant deficiencies in acute in-hospital stroke management in Sri Lanka. ${ }^{8}$ There is very little organised structure for acute stroke care, and multidisciplinary stroke rehabilitation services for disabled survivors are virtually non-existent in the community. ${ }^{9}$

Stroke prevention is the most cost effective way of minimising the burden of stroke in a resource-limited country such as Sri Lanka. Promotion of good preventive practices would require a high level of stroke awareness in the community. Knowledge regarding stroke positively influences treatment seeking behaviour and stroke risk reduction behaviour. ${ }^{10,11}$ Previous studies have consistently highlighted deficiencies of knowledge of stroke in different communities worldwide. Data on stroke awareness 
from developing countries are scarce, and there are no published data from Sri Lanka. The objective of the present study was to assess stroke awareness in a Sri Lankan community.

\section{Methods}

This study was part of a community survey on stroke conducted in the Kelaniya Medical Officer of Health area in 2001/2002. ${ }^{4}$ Adults and schoolchildren over grade 6 in 750 households in the Kelaniya Medical Officer of Health area, selected by a 2-stage cluster sampling technique, formed the study sample.

Knowledge about stroke was assessed using a 40-item, structured, interviewer administered questionnaire. The questionnaire was pre-tested in a pilot study of 50 households. Knowledge was assessed regarding pathogenesis, symptoms, important modifiable risk factors, preventive behaviour and treatment options. Level of knowledge was converted to a score out of 100 , and categorised into 5 groups as follows: $81-100$ - Very good; 61-80 - Good; 41-60 - Average; 21-40 Poor and 0-20 - Very poor. Sources of any previous information received were recorded.

Prior ethical approval for the study was obtained from the Ethical Review Committee of the Sri Lanka Medical Association, and administrative approval was obtained from the Provincial Director of Health, Western Province.

\section{Results}

We interviewed all adults and eligible schoolchildren present at the time of the household visit. A total of 866 individuals (711 adults and 155 school children) responded to the questionnaire. The mean age of the study population was 38.2 years (adults 44.2 years, schoolchildren 14.8 years).
Only $36.8 \%$ correctly identified the brain as the organ involved in a stroke, while $12.5 \%$ thought the heart was primarily involved, and $40.5 \%$ did not know. Lack of blood supply to the brain was identified as a possible mechanism of stroke by $32.8 \%$, and bleeding into the brain by $26 \%$. Knowledge regarding presenting symptoms and risk factors showed variable results. Main symptoms identified were unilateral weakness (93.9\%), unilateral sensory symptoms (88\%) and difficulty in speech (88\%). Many recognised hypertension (74.3\%) as a risk factor, but awareness was inadequate regarding heart disease $(60.9 \%)$, diabetes $(60.5 \%)$, high cholesterol levels (62.5\%) and smoking (61.3\%) (Table 1). Knowledge regarding strategies for prevention was better (Table 2).

Stroke was considered a cause of sudden death by $58.4 \%$. Only $60.1 \%$ thought stroke was preventable, and $74 \%$ were aware that stroke could recur. Majority (91.3\%) believed early treatment would improve outcome, $88.8 \%$ considered stroke an emergency, but only $67.7 \%$ felt that Western (allopathic) treatment was beneficial.

Level of knowledge was considered 'Very good' in only $0.7 \%$, and 'Good' in $43.3 \%$. More than half the study population (56\%) were rated to have 'Average', 'Poor' or 'Very poor' knowledge (Table 3). There was no significant difference in knowledge between adults and schoolchildren $(p=0.38)$, or between those $<60$ years and $\geq 60$ years of age $(p=0.06)$.

A total of 643 individuals (74.3\%) had received some information about stroke previously (542 adults - 76.2\%, 101 school children - 65.2\%). Having a friend or a relative with a stroke was the commonest source of knowledge (61.6\%). Media, doctors and other health workers were poor sources of information (Table 4).

Table 1. Awareness of modifiable risk factors for stroke

\begin{tabular}{lllllll}
\hline Risk factors & \multicolumn{2}{c}{ Adults } & \multicolumn{2}{c}{ School children } & \multicolumn{2}{c}{ Total } \\
& no. & $\%$ & no. & $\%$ & no. & $\%$ \\
\hline Hypertension & 544 & 76.5 & 99 & 63.9 & 643 & 74.3 \\
Heart disease & 431 & 60.6 & 96 & 61.9 & 527 & 60.9 \\
Diabetes & 437 & 61.5 & 87 & 56.1 & 524 & 60.5 \\
High cholesterol & 457 & 64.2 & 84 & 54.2 & 541 & 62.5 \\
Smoking & 436 & 61.3 & 95 & 61.3 & 531 & 61.3 \\
Alcohol excess & 480 & 67.5 & 104 & 67.1 & 584 & 67.4 \\
Obesity & 393 & 55.3 & 62 & 40.0 & 455 & 52.5 \\
\hline
\end{tabular}


Table 2. Knowledge regarding preventive behaviour

\begin{tabular}{lcccccc}
\hline $\begin{array}{l}\text { Stroke can be } \\
\text { prevented by }\end{array}$ & \multicolumn{2}{c}{ Adults } & \multicolumn{2}{c}{ School children } & \multicolumn{2}{c}{ Total } \\
& no. & $\%$ & no. & $\%$ & no. & $\%$ \\
\hline treating hypertension & 590 & 83.0 & 128 & 82.5 & 718 & 82.9 \\
treating diabetes & 556 & 78.2 & 120 & 77.4 & 676 & 78.1 \\
stopping smoking & 503 & 70.3 & 110 & 71.0 & 613 & 70.8 \\
limiting alcohol & 520 & 73.1 & 120 & 77.4 & 640 & 73.9 \\
exercise & 536 & 75.4 & 114 & 73.5 & 650 & 75.1 \\
low salt diet & 472 & 66.4 & 98 & 63.2 & 570 & 65.8 \\
low fat diet & 464 & 65.2 & 113 & 72.9 & 577 & 66.6 \\
\hline
\end{tabular}

Table 3. Levels of knowledge

\begin{tabular}{|c|c|c|c|c|c|c|}
\hline \multirow{2}{*}{$\begin{array}{l}\text { Level of } \\
\text { knowledge }\end{array}$} & \multicolumn{2}{|c|}{ Adults } & \multicolumn{2}{|c|}{ School children } & \multicolumn{2}{|c|}{ Total } \\
\hline & no. & $\%$ & no. & $\%$ & no. & $\%$ \\
\hline Very good (81-100) & 4 & 0.6 & 2 & 1.3 & 6 & 0.7 \\
\hline Good (61-80) & 309 & 43.5 & 66 & 42.6 & 375 & 43.3 \\
\hline Average (41-60) & 328 & 46.2 & 77 & 49.6 & 405 & 46.8 \\
\hline Poor (21-40) & 43 & 6.1 & 8 & 5.2 & 51 & 5.9 \\
\hline Very poor (0-20) & 27 & 3.8 & 2 & 1.3 & 29 & 3.3 \\
\hline
\end{tabular}

Table 4. Sources of knowledge

\begin{tabular}{lcccccc}
\hline $\begin{array}{l}\text { Sources of } \\
\text { knowledge }\end{array}$ & \multicolumn{2}{c}{$\begin{array}{c}\text { Adults } \\
\text { no. }\end{array}$} & $\%$ & \multicolumn{2}{c}{ School children } & \multicolumn{2}{c}{ Total } \\
\hline TV & 364 & 51.2 & no. & $\%$ & no. & $\%$ \\
Newspapers & 295 & 41.5 & 49 & 31.6 & 344 & 39.7 \\
Radio & 287 & 40.4 & 49 & 31.6 & 336 & 38.8 \\
Friend/relative with stroke & 488 & 68.6 & 45 & 29.0 & 533 & 61.5 \\
School & 134 & 18.9 & 69 & 44.5 & 203 & 23.4 \\
Doctors & 248 & 34.9 & 31 & 20.0 & 279 & 32.2 \\
Other health professional & 68 & 9.6 & 11 & 7.1 & 79 & 9.1 \\
\hline
\end{tabular}

\section{Discussion}

Stroke awareness is a key determinant of health promoting behaviour. Life style modification and risk factor control are the cornerstones of stroke prevention, and these are dependent on awareness of modifiable risk factors and healthy life style changes. Awareness of warning symptoms and the need for early treatment are important for early symptom recognition and early hospital admission. ${ }^{10,11}$

Studies on stroke awareness have been conducted in many parts of the world, but only a few reports are available from South Asia, in spite of its 
disproportionately high burden of stroke. ${ }^{12-15}$ We present data on stroke awareness in a Sri Lankan community. To our knowledge, this is the first report on stroke awareness from Sri Lanka.

This study has highlighted many areas of deficient knowledge on stroke in this community setting. Studies of stroke awareness conducted elsewhere have produced broadly similar results. Many respondents (50-74\%) in different parts of the world have failed to recognise that stroke primarily affects the brain, ${ }^{12,15-}$ $17,20-22$ and a number of patients (16\%) have thought that stroke was due to an injury to the heart. ${ }^{10}$

Previous studies have highlighted deficiencies in knowledge regarding early stroke symptoms. Unilateral weakness, perhaps the best known of all stroke symptoms, was recognised as a stroke symptom by only a few respondents (6-15\%) in some studies. ${ }^{22,23}$ Many patients (30-66\%) were unable to recognise at least one of the common stroke warning symptoms. ${ }^{10,13,16,17,20,22,24,27,28}$ Knowledge regarding stroke risk factor recognition too is reported to be poor. Hypertension (23-74\%) and smoking (27-50\%) are the main risk factors identified in previous studies. 10,12,13,15,21,22,25-29 Recognition of early stroke symptoms and awareness of stroke risk factors in our study appeared to be better than in most studies. Previous studies have noted poor knowledge in older age groups, ${ }^{13,16,17,19,20,22,26,30}$ but we did not find a significant difference in knowledge with age.

The main sources of knowledge in our study were life experiences such as stroke victims in the family or the neighbourhood, or friends and relatives. Similar findings were noted in some previous studies. ${ }^{10,15,17}$ In contrast, other studies have noted media, especially television, to be the main source of knowledge. ${ }^{16,22}$ Interestingly, the contribution of the health care professionals to stroke awareness has been rather limited in many of these studies..$^{10,16,19,22}$

This study has several limitations that need to be acknowledged. We did not assess knowledge according to level of education or socioeconomic status. Other studies have noted poor knowledge with low educational and socioeconomic status. ${ }^{12,13,16,19,20,26,27,29,31}$ The questionnaire did not test free recall, and a list of options was given for each question. Previous studies, however, have observed that assessment of knowledge was poor with free recall, and improvements in results were noted when a list of options was provided. ${ }^{19,32}$ Even with a series of optional responses being available, the knowledge on stroke in our study was rather modest at best.

Several strengths in our study are worth highlighting. Many previous studies have been conducted among patients with stroke in hospital settings. ${ }^{13,14,17,21,28,30,33,34-37}$ Our study focussed on individuals in the community, and included schoolchildren, a group which to our knowledge has not been tested previously. Knowledge of stroke symptoms and risk factors in the community are more likely to be important in determining health seeking patterns and preventive behaviour. We categorised stroke awareness according to a composite score, enabling quantification of knowledge, and comparisons between different groups.

In conclusion, stroke awareness in our community remains deficient in many aspects, although our respondents fared better in some areas compared to studies conducted in other countries. There is a clear need to develop community based public educational programmes to improve knowledge of stroke, and to promote healthy life styles, risk reduction behaviour and appropriate treatment seeking behaviour.

It is possible that the current level of stroke awareness in this community would be different, compared to the time of the study. With the recent advances in stroke care and the increasing availability of health messages via different media, an improved level of awareness would be expected. More research is needed to compare these findings with the current state of awareness at community level, as well as among stroke victims and those at high risk of stroke.

\section{Acknowledgements}

We wish to acknowledge Dr Rajitha Wickramasinghe for statistical assistance, and the National Stroke Association of Sri Lanka for supporting Drs. Janitha Balasuriya, Himali de Silva and Buddhi Jayasekara.

\section{Conflicts of interests \\ None}

\section{References}

1. Murray CTL, Lopez AD. Mortality by cause for eight regions of the world: Global Burden of Disease Study. Lancet 1998; 349: 1269-76.

2. Ministry of Healthcare and Nutrition, Sri Lanka. Annual Health Bulletin 2012.

3. Hankey GJ. Stroke: How large a public health problem, and how can the neurologist help? Archives of Neurology 1999; 56: 748-54.

4. Ranawka U, de Silva $\mathrm{H}$, Balasuriya J, et al. Prevalence of stroke in a Sri Lankan community - A door-to-door survey. Neurology 2007; 68: A103.

5. Chang T, Gajasinghe S, Arambepola C. Prevalence of Stroke and Its Risk Factors in Urban Sri Lanka: Population-Based Study. Stroke 2015; 46: 2965-8. 
6. de Silva WI. How serious is ageing in Sri Lanka, and what can be done about it? Asia Pacific Population Journal 1994; 9: 19-36.

7. Singh RB, Suh IL, Singh VP, et al. Hypertension and stroke in Asia: prevalence, control and strategies in developing countries for prevention. Journal of Human Hypertension 2000; 14: 749-63.

8. Ranawaka UK, Fernando MAH, Gunasekera TGSM, et al. An audit of acute stroke care at the Institute of Neurology, National Hospital of Sri Lanka, 1994-1997. Ceylon Medical Journal 2002; 47: 86-9.

9. Ranawaka UK, Wijesekera JC. Caring for patients with stroke. Journal of the Ceylon College of Physicians 2000; 33: 153-4.

10. Yoon SS, Helter RF, Levi C, Wiggers J, Fitzgrald PE. Knowledge of stroke risk factors, warning symptoms, and treatment in an Australian urban population. Stroke 2001; 32: 1926-30.

11. Hachinski V. Awareness: the first step to action. Stroke 2002; 33: 1173.

12. Pandian JD, Jaison A, Deepak SS, et al. Public awareness of warning symptoms, risk factors, and treatment of stroke in northwest India. Stroke 2005; 36: 644-8.

13. Pandian JD, Kalra G, Jaison A, et al. Knowledge of stroke among stroke patients and their relatives in Northwest India. Neurology India 2006; 54: 152-6.

14. Das K, Mondal GP, Dutta AK, Mukherjee B, Mukherjee BB. Awareness of warning symptoms and risk factors of stroke in the general population and in survivors stroke. Journal of Clinical Neurosciences 2007; 14: 12-6.

15. Aly Z, Abbas K, Kazim SF, et al. Awareness of stroke risk factors, signs and treatment in a Pakistani population. Journal of the Pakistan Medical Association 2009 ; 59: 495-9.

16. Pancioli AM, Broderick J, Kothari R, et al. Public perception of stroke warning signs and knowledge of potential risk factors. Journal of the American Medical Association 1998; 279: 1288-92.

17. Kothari R, Sauerbeck L, Jauch E, et al. Patient's awareness of stroke signs, symptoms and risk factors. Stroke 1997; 28: $1871-5$.

18. Cheung RTF, Li LSW, Mak W, et al. Knowledge of stroke in Hong Kong Chinese. Cerebrovascular Diseases 1999; 9: 119-23.

19. Nicol MB, Thrift AG. Knowledge of risk factors and warning signs of stroke. Vascular Health and Risk Management 2005; 1: 137-47.

20. Al Shafaee MA, Ganguly SS, Al Asmi AR. Perception of stroke and knowledge of potential risk factors among Omani patients at increased risk for stroke. BMC Neurology 2006; 6: 38.

21. Maasland L, Koudstaal PJ, Habbema JD, Dippel DW. Knowledge and understanding of disease process, risk factors and treatment modalities in patients with a recent TIA or minor ischemic stroke. Cerebrovascular Diseases 2007; 23: 435-40.
22. Schneider AT, Pancioli AM, Khoury JC, et al. Trends in community knowledge of the warning signs and risk factors for stroke. Journal of the American Medical Association 2003; 289: 343-6.

23. Brice JH, Griswell JK, Delbridge TR, Key CB. Stroke: from recognition by the public to management by emergency medical services. Prehospital Emergency Care 2002; 6: 99-106.

24. Wahab KW, Okokhere PO, Ugheoke AJ, et al. Awareness of warning signs among suburban Nigerians at high risk for stroke is poor: a cross-sectional study. BMC Neurology 2008; 8: 18.

25. Kamran S, Bener AB, Deleu D, et al. The level of awareness of stroke risk factors and symptoms in the Gulf Cooperation Council countries: Gulf Cooperation Council stroke awareness study. Neuroepidemiology 2007; 29: 235-42.

26. Blades LL, Oser CS, Dietrich DW, et al. Rural community knowledge of stroke warning signs and risk factors. Preventing Chronic Disease 2005; 2: A19.

27. Pontes-Neto OM, Silva GS, Feitosa MR, et al. Stroke awareness in Brazil: alarming results in a community-based study. Stroke 2008; 39: 292-6.

28. Derex L, Adeleine P, Nighoghossian N, Honnorat J, Trouillas P. Knowledge of strokes in patients admitted to a French Stroke Unit. Revue Neurologique 2004; 160: 331-7.

29. Anne Hickey, Ann O'Hanlon, Hannah McGee et al. Stroke awareness in the general population: knowledge of stroke risk factors and warning signs in older adults. BMC Geriatrics 2009; 9: 35.

30. Croquelois A, Bogousslavsky J. Risk awareness and knowledge of patients with stroke: results of a questionnaire survey 3 months after stroke. Journal of Neurology Neurosurgery and Psychiatry 2006; 77: 726-8.

31. Nedeltchev K, Fischer U, Arnold M, Kappeler L, Mattle HP. Low awareness of transient ischemic attacks and risk factors of stroke in a Swiss urban community. Journal of Neurology 2007; 254:179-84.

32. Jones SP, Jenkinson AJ, Leathley MJ, Watkins CL. Stroke knowledge and awareness: an integrative review of the evidence. Age and Ageing 2010; 39:11-22.

33. Stead LG, Vaidyanathan L, Bellolio MF, et al. Knowledge of signs, treatment and need for urgent management in patients presenting with an acute ischaemic stroke or transient ischaemic attack: a prospective study. Emergency Medicine Journal 2008; 25: 735-9.

34. Williams LS, Bruno A, Rouch D, Marriott DJ. Stroke patients' knowledge of stroke. Influence on time to presentation. Stroke 1997; 28: 912-5.

35. Barr J, McKinley S, O'Brien E, Herkes G. Patient recognition of and response to symptoms of TIA or stroke. Neuroepidemiology 2006; 26: 168-75.

36. Yoon SS, Byles J. Perceptions of stroke in the general public and patients with stroke: a qualitative study. British Medical Journal 2002; 324: 1065-8.

37. Wellwood I, Dennis MS, Warlow CP. Perceptions and knowledge of stroke among surviving patients with stroke and their carers. Age and Ageing 1994; 23: 293-8. 